\title{
GENE FOR MONOAMINE OXIDASE TYPE A ASSIGNED TO THE HUMAN X CHROMOSOME ${ }^{1}$
}

\author{
JOHN E. PINTAR, JAMES BARBOSA, UTA FRANCKE, CARMELA M. CASTIGLIONE, \\ MORRIS HAWKINS, JR., ${ }^{2}$ AND XANDRA O. BREAKEFIELD ${ }^{3}$
}

Department of Human Genetics, Yale University School of Medicine, New Haven, Connecticut 06510

\begin{abstract}
Inherited variations in monoamine oxidase (MAO) activity are thought to affect human behavior and expression of disease. The present study has established the chromosomal location of one of the structural genes coding for this enzyme. Mapping was carried out by somatic cell hybridization between normal human skin fibroblasts and mouse neuroblastoma cells. Selective media for growth of cells with or without hypoxanthine phosphoribosyltransferase (HPRT) activity were used to obtain hybrid lines which had retained or lost the human $\mathrm{X}$ chromosome, respectively. Cytogenetic techniques, isozyme analysis, and limited proteolysis and peptide mapping of $\left[{ }^{3} \mathrm{H}\right]$ pargyline-labeled MAO were used to characterize hybrid lines. With one exception, only lines containing the human X chromosome and human forms of two Xlinked enzymes (phosphoglycerate kinase and glucose-6-phosphate dehydrogenase) expressed the human form of the flavin polypeptide of type A MAO. The exceptional hybrid line contained a putative translocation of part of the human X chromosome, since it expressed human forms of both MAO and phosphoglycerate kinase but neither the human form of glucose-6-phosphate dehydrogenase nor HPRT activity. This evidence indicates that the structural gene for the flavin polypeptide of MAO-A is on the human X chromosome. This represents the first chromosomal assignment of a human gene coding for an enzyme of neurotransmitter metabolism. This information will help to elucidate the structure of MAO and modes of its inheritance in the human population.
\end{abstract}

Inherited variations in the activity of enzymes involved in neurotransmitter metabolism are thought to affect individual differences in neurophysiology, behavior, and susceptibility to disease. In order to understand the molecular basis of these variations, it is necessary to establish the number of genes and the nature of the gene products critical to expression of these enzymes. Knowledge of the chromosomal location of genes involved in neurotransmitter metabolism should contribute to this understanding.

Monoamine oxidase (MAO, EC 1.4.3.4) is the enzyme primarily responsible for degradative deamination of biogenic amine transmitters in the nervous system (for reviews, see Murphy, 1978; Houslay et al., 1976). Two types of activity have been distinguished on the basis of substrate affinity and drug sensitivity. Type $\mathrm{A}$ has a higher affinity for norepinephrine and serotonin and is

\footnotetext{
${ }^{1}$ We thank Muriel Braverman, Virginia Bonnefil, Richard Cawthon, Helen Chao, Pavia Tetri, and Richard Wetts for their help in these studies; Dr. June Biedler for providing human neuroblastoma cells; and Nancy Dillon for skilled preparation of the manuscript. This work was supported by United States Public Health Service Grants NS12105 and GM20124 to X. O. B. and GM26105 to U. F.

${ }^{2}$ Present address: Department of Microbiology, Howard University College of Medicine, Washington, DC 20059.

"To whom correspondence should be addressed.
}

inhibited by lower concentrations of clorgyline; type B has a higher affinity for phenylethylamine and benzylamine and is inhibited by lower concentrations of deprenyl. These types of activity differ in their tissue distribution and developmental expression. Both types are active in the human nervous system (Owen et al., 1979; Oreland and Fowler, 1979).

Monoamine oxidase is an integral membrane protein located in the outer mitochondrial membrane (Sottocasa et al., 1967). It is thought to be a dimer composed of two subunits of approximately equal molecular weight (about 60,000 daltons), one of which bears a covalently attached flavin cofactor (Oreland et al., 1973; Collins and Youdim, 1975; Minamiura and Yasunobu, 1978). This flavin polypeptide can be analyzed by gel electrophoresis following covalent binding of the irreversible inhibitor $\left[{ }^{3} \mathrm{H}\right]$ pargyline (Hellerman and Erwin, 1968; Chuang et al., 1974). The flavin polypeptides associated with $A$ and $B$ types of activity differ in apparent molecular weight (Callingham and Parkinson, 1979; R. M. Cawthon, J. E. Pintar, F. P. Haseltine, M. S. Buchsbaum, D. L. Murphy, and X. O. Breakefield, submitted for publication) and specific proteolytic cleavage sites (Cawthon and Breakefield, 1979) and may be the products of separate gene loci. No information is available on the structure of the non-flavincontaining polypeptide.

In the present study, techniques of somatic cell ge- 
netics were utilized to map the chromosomal location of the human gene coding for the flavin polypeptide associated with type A MAO activity. Hybrid cells were prepared by fusing normal human skin fibroblasts, which express predominantly the A type of MAO activity (Roth et al., 1976; Groshong et al., 1977), with a variant line of mouse neuroblastoma cells which lack MAO activity (Breakefield et al., 1976). Individual human chromosomes retained in hybrids were identified by Giemsa staining; human and rodent isozymes of phosphoglycerate kinase (PGK, EC 2.7.2.3) and glucose-6-phosphate dehydrogenase (G6PD, EC 1.1.1.49) were resolved by electrophoretic techniques; and human and rodent forms of the flavin polypeptide of MAO were distinguished on the basis of peptide maps generated by limited proteolysis of $\left[{ }^{3} \mathrm{H}\right]$ pargyline-labeled molecules.

\section{Materials and Methods}

Cell culture. Human skin fibroblasts from a normal male were obtained from the Human Genetic Mutant Cell Repository (GM316, Institute for Medical Research, Camden, NJ). Mouse neuroblastoma line N1E-115 (Amano et al., 1972) was obtained from Dr. Marshall Nirenberg (National Institutes of Health, Bethesda, MD). Line N1E-115TG2 was cloned from N1E-115 in the presence of $0.1 \mathrm{~mm}$ 6-thioguanine (6TG) to select for loss of hypoxanthine phosphoribosyltransferase (HPRT, EC 2.4.2.8) activity (Breakefield et al., 1976). Human neuroblastoma line $\mathrm{BE}(2) \mathrm{C}$ was provided by Dr. June Biedler (Sloan-Kettering Institute, Rye, NY). Cells were grown in Dulbecco's modified Eagle's medium (DMEM, GIBCO) supplemented with $5 \%$ fetal calf serum (Flow), as previously described (Edelstein et al., 1978), unless otherwise indicated. Cells with HPRT activity were selected by growth in medium containing $0.1 \mathrm{~mm}$ hypoxanthine, $10 \mu \mathrm{M}$ aminopterin, and $40 \mu \mathrm{M}$ thymidine (HAT; Littlefield, 1964). In hybridization experiments, human parental cells were selected against by addition of $0.2 \mu \mathrm{M}$ ouabain (Mankovits et al., 1974). All lines are stored viably in liquid nitrogen.

Hybrids were prepared by mixing $5 \times 10^{6}$ fibroblasts and $5 \times 10^{6} \mathrm{~N} 1 \mathrm{E}-115 \mathrm{TG} 2$ cells in $1 \mathrm{ml}$ of DMEM containing 500 hemagglutinating units of inactivated Sendai virus, as described (Giles and Ruddle, 1973). Cells were plated at several densities $\left(0.5\right.$ to $5 \times 10^{5} / 100-\mathrm{mm}$ tissue culture dish) in DMEM with $10 \%$ fetal calf serum. Two days later, the medium was changed to DMEM with 5\% fetal calf serum containing HAT and ouabain to select against growth of the neuroblastoma and fibroblast parental cells, respectively. After 2 weeks, hybrid lines were isolated as colony clones from separate dishes with the aid of Penicylinders (Fisher). Hybrid colonies appeared at a frequency of about five per $2.5 \times 10^{5}$ parental cells plated. After three to five subcultures in medium containing HAT, but no ouabain, two of these hybrid clones (NGM1 and NGM5) were recloned in DMEM with 5\% fetal calf serum. After three to five subcultures in nonselective medium, two of these clones (NGM1E1 and NGM5F1) were cloned again in the presence of $6 \mathrm{TG}$ or HAT yielding lines designated NGM1E1TG1A, NGM1E1HAT1A, etc. Hybrids were analyzed using cells from parallel cultures.

Enzyme assays. Cultures were grown to 80 to $90 \%$ confluency in the designated medium, then in two changes of nonselective medium at 24-hr intervals prior to harvesting. For cultures in HAT, the first change was with medium containing hypoxanthine and thymidine but no aminopterin. Cells were rinsed with isotonic phosphate-buffered saline and removed from the dish by scraping (Hawkins and Breakefield, 1978) into a small volume of the same buffer. Cell suspensions were centrifuged at $8000 \times g$ for 2 min and cell pellets were frozen at $-65^{\circ} \mathrm{C}$. Prior to analysis, the cells were resuspended in the appropriate buffer and homogenized by sonication, as described (Hawkins and Breakefield, 1978).

MAO activity was measured against saturating concentrations of $\left[{ }^{3} \mathrm{H}\right]$ tryptamine by a modification (Costa et al., 1980) of the method of Wurtman and Axelrod (1963). To establish the type of MAO activity, cell homogenates were preincubated with clorgyline (Abbott Laboratories) over a range of concentrations from $1 \mathrm{~mm}$ to $0.1 \mathrm{fm}$ (Hawkins and Breakefield, 1978). Homogenates were assayed in triplicate at two protein concentrations within the range of linearity with respect to time and protein.

Hypoxanthine phosphoribosyltransferase activity was determined by a modification (Roth et al., 1976) of the method of Kelley et al. (1967), except that $0.12 \mathrm{~mm}$ $\left[{ }^{14} \mathrm{C}\right]$ hypoxanthine was used and reactions were incubated for $30 \mathrm{~min}$. The amount of $\left[{ }^{14} \mathrm{C}\right]$ inosinic acid formed was determined by binding to DEAE-cellulose discs (Degnen et al., 1976). Cell extracts were assayed in triplicate at two protein concentrations within the range of linearity with respect to time and protein.

Protein concentrations were determined by the method of Bradford (1976) using bovine serum albumin as standard.

Isozyme analysis. The presence of mouse and human forms of phosphoglycerate kinase (PGK) and glucose-6phosphate dehydrogenase (G6PD) in cell homogenates was determined by electrophoresis on cellulose acetate using a commercial Cellogel apparatus (Chemetron) and histochemical stains for enzyme activity (Meera Khan, 1971).

Chromosome analysis. Logarithmically growing cells were arrested in metaphase by treatment with $0.4 \mathrm{~mm}$ Colcemid. Chromosome preparations were spread onto slides, air dried, and baked at $95^{\circ} \mathrm{C}$ for 10 to $20 \mathrm{~min}$; individual chromosomes were identified by Giemsa banding patterns following brief treatment with $0.05 \%$ trypsin and staining with $0.06 \%$ Giemsa solution at $\mathrm{pH} 7.0$ (Francke and Oliver, 1978). Human and mouse chromosomal material was distinguished by a modification of the Giemsa-11 technique (Magenis et al., 1978) in which staining is carried out at $\mathrm{pH} 11.3$ using only two components $(0.012 \%$ azure $\mathrm{B}$ and $0.0025 \%$ eosin $\mathrm{Y})$ of the Giemsa dye.

Electrophoretic analysis of MAO. Crude mitochondrial fractions were prepared from cell lines and MAO was specifically laheled with $\left[{ }^{3} \mathrm{H}\right]$ pargyline (New England Nuclear) as described (Costa and Breakefield, 1979). In some cases, fractions were incubated with $1 \mu \mathrm{M}$ deprenyl (Dr. J. Knoll, Sammelweis University, Budapest, Hungary) or $0.1 \mu \mathrm{M}$ clorgyline (Abbott Laboratories) for 10 min at $37^{\circ} \mathrm{C}$ prior to incubation with $\left[{ }^{3} \mathrm{H}\right]$ pargyline, to block labeling of MAO-B and MAO-A, respectively. A and $\mathrm{B}$ forms of the $\left[{ }^{3} \mathrm{H}\right]$ pargyline-labeled flavin polypep- 
tides were separated on the basis of apparent molecular weight using sodium dodecyl sulfate (SDS)-polyacrylamide gel electrophoresis (PAGE) and fluorography (R. M. Cawthon et al., submitted for publication). Limited proteolysis and peptide mapping of labeled flavin polypeptides was carried out by a modification (Cawthon and Breakefield, 1979) of the method of Cleveland et al. (1977) using varying amounts of Staphylococcus aureus V8 protease. The distribution of radioactivity in gels was determined by a modification of the method of Horvitz (1973) recommended by New England Nuclear.

\section{Results}

MAO and HPRT activities in parental lines. The mouse neuroblastoma line N1E-115TG2 used as one of the parental cell types in the hybridization was selected for loss of HPRT activity from line N1E-115 in medium containing 6TG. Line N1E-115TG2 has $<1 \%$ HPRT activity of line N1E-115 (Breakefield et al., 1976) and undetectable levels of MAO activity (Table I). In contrast, line N1E-115 has relatively high levels of MAO activity (Table I) (exclusively of the A type; Donnelly et al., 1976). The simultaneous loss of HPRT and MAO activities in N1E-115TG2 cells originally suggested a biochemical connection between these two enzymes. However, selection for revertants of N1E-115TG2 cells with restored HPRT activity (by growth in medium containing HAT) did not result in recovery of MAO activity (Breakefield et al., 1979). Since the gene for HPRT is on the $\mathrm{X}$ chromosome in the mouse (Epstein, 1969) (as well as the human; Nabholz et al., 1969; Shows et al., 1976), another explanation for the simultaneous loss of HPRT and MAO activities in line N1E-115TG2 might be that a chromosomal event occurred involving a segment of the $\mathrm{X}$ chromosome containing loci for both enzymes.

The human fibroblast line GM316 used as the other parental cell type was obtained from a normal male and hence cells contain a single $\mathrm{X}$ chromosome. These cells express moderate levels of MAO activity (Table I), pre-

TABLE I

$M A O$ activities in parental lines and HAT-selected hybrid clones

\begin{tabular}{lcc}
\hline \multicolumn{1}{c}{ Lines } & \multicolumn{2}{c}{ MAO } \\
\hline & & \\
Parents & $<0.05$ & $(5)^{n}$ \\
N1E-115TG2 & $103.0 \pm 9.0$ & $(5)^{h}$ \\
N1E-115 & $24.5 \pm 2.1$ & $(12)$ \\
GM316 & & \\
& & \\
Hybrids & $28.4 \pm 11.5$ & $(3)$ \\
NGM1 & $13.8 \pm 9.0$ & $(3)$ \\
NGM2 & $3.6,4.3$ & \\
NGM4 & $75.6,150.0$ & \\
NGM5 & $1.3 \pm 1.0$ & $(3)$ \\
NGM6 & $0.4 \pm 0.1$ & $(4)$ \\
NGM7 & $1.6 \pm 1.0$ & $(4)$ \\
NGM9 & $4.5 \pm 1.6$ & $(3)$ \\
NGM10
\end{tabular}

"Values are given as mean \pm SEM. The number in parentheses is number of separate homogenates assayed. When only two values are available, they are listed separately.

${ }^{b}$ From Breakefield et al., 1976. dominantly of the A type, as well as normal levels of HPRT activity (data not shown).

MAO and HPRT activities in hybrids. Hybrids between N1E-115TG2 and GM316 cells were cloned initially in medium containing HAT. Although human chromosomes were lost randomly during initial divisions of these hybrid cells, this medium selected for cells which expressed HPRT activity and hence retained the human $\mathrm{X}$ chromosome. In the initial set of seven hybrid lines examined, all expressed MAO activity. The levels ranged from 0.4 (less than that of the human fibroblast) to 112.8 $\mathrm{pmol} / \mathrm{min} / \mathrm{mg}$ of protein (similiar to N1E-115) (Table I). Thus, the lesion causing loss of MAO activity in N1E115TG2 cells was not phenotypically dominant, i.e., it did not block expression of this enzyme in hybrids. Further, expression of MAO activity in hybrids appeared to correlate with retention of the human $\mathrm{X}$ chromosome.

Four hybrid lines were chosen for further studies; two expressed very low and two expressed very high MAO activities. Lines were recloned to allow further loss of human chromosomes and to achieve cell populations with more homogeneous karyotypes. Recloning of the two low lines, NGM7 and NGM9 (MAO activity, 0.4 and $1.6 \mathrm{pmol} / \mathrm{min} / \mathrm{mg}$ of protein, respectively) in HAT medium, yielded four lines, NGM7A1, NGM7B1, NGM9A1, and NGM9B2, with somewhat higher levels of $M \Lambda O$ activity, $5.7,6.2,7.6$, and $5.2 \mathrm{pmol} / \mathrm{min} / \mathrm{mg}$ of protein, respectively (single determinations). The higher MAO activity may result from loss of additional human chromosomes and retention of the human X chromosome in a larger percentage of the cells (see below). Recloning of the two high lines, NGM1 and NGM5 (MAO activity, 28.4 and $112.8 \mathrm{pmol} / \mathrm{min} / \mathrm{mg}$ of protein, respectively) in nonselective medium, yielded nine lines from each, all with high MAO activity ranging from 10.5 to $330.0 \mathrm{pmol} /$ $\mathrm{min} / \mathrm{mg}$ of protein (duplicate determinations). Two of these recloned lines with high activity, NGM1E1 and NGM5F1 (Table II), were cloned again in medium containing 6TG to establish whether selection for loss of HPRT activity (i.e., loss of the human X chromosome) would result in loss of MAO activity. Of 10 hybrid clones grown in 6TG, nine lost MAO activity, while one, NGM5F1D2, retained levels comparable to the line NGM5F1 from which it was derived (Table II). In contrast, recloning of line NGM1E1 in HAT medium yielded two clones with high MAO activity (Table II).

The type of MAO activity expressed in hybrids was evaluated in the fibroblast parental line, GM316, and hybrids, NGM7, NGM9, NGM1E1HAT2B, NGM5F1, and NGM5F1D2, by the dose-dependent inhibition of tryptamine deamination by clorgyline. All lines showed a monophasic inhibition curve with at least $90 \%$ of activity being inhibited by $0.1 \mu \mathrm{M}$ clorgyline which is consistent with the predominant activity being type $\mathrm{A}$.

In all cases, hybrid clones which were able to grow in HAT medium had high levels of HPRT activity, while those which grew in 6TG medium had low levels $(<1 \%$ high values) of activity (Table II).

Chromosome analysis. The parental neuroblastoma line is a heteroploid line containing a modal chromosome number of 134 and many chromosomal rearrangements. Sixteen hybrid lines were examined karyotypically, using Giemsa banding to identify individual chromosomes. 
TABLE II

Analysis of NGM hybrids

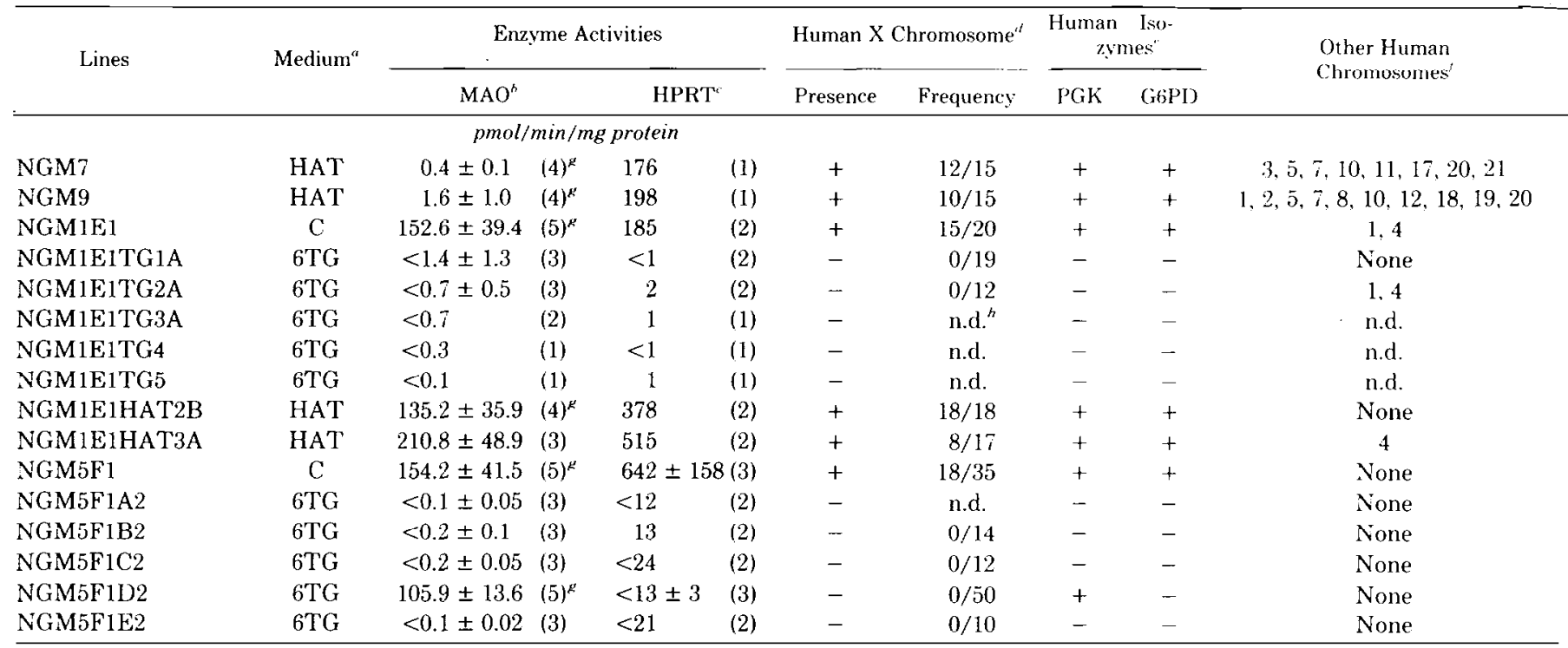

${ }^{a}$ Medium used during cloning and growth of linés. C refers to DMEM with $5 \%$ fetal calf serum. Concentrations of $6 \mathrm{TG}$ and $\mathrm{HAT}$ added to this medium are provided under "Materials and Methods."

${ }^{b}$ Values obtained from assay of separate homogenates $(N)$. When more than three homogenates were assayed, values are given as the mean \pm SEM; for two homogenates, the mean is listed. The lower limit of detection varied from 0.05 to $0.7 \mathrm{pmol} / \mathrm{min} / \mathrm{mg}$ of $\mathrm{protein} \mathrm{depending}$ on the amount of homogenate protein assayed.

"Values are listed as described for MAO. The lower limit of detection varied from 1 to $35 \mathrm{pmol} / \mathrm{min} / \mathrm{mg}$ of protein depending on the amount of homogenate protein assayed and the number of assays run simultaneously (more samples gave higher backgrounds).

"The presence of the human X chromosome was determined by scanning metaphase chromosome spreads stained by the Giemsa banding technique. Frequency refers to the number of spreads with a human $X$ chromosome over the total number of spreads examined.

${ }^{e}$ Human forms of these enzymes were detected by electrophoresis on cellulose acetate thin laver sheets, followed by specific staining for enzyme activity (Meera Khan, 1971).

The presence of other human chromosomes observed in at least $50 \%$ of metaphase spreads examined.

"Activity was inhibited completely by preincubation of homogenates with $1 \mu \mathrm{M}$ clorygline.

${ }^{h}$ n.d., not done.

Nine hybrids with MAO activity had at least one human $\mathrm{X}$ chromosome present in most cells (Fig. 1); six with no $\mathrm{MAO}$ activity lacked a human X chromosome in all cells examined (Table II and J. E. Pintar, J. Barbosa, U. Francke, C. M. Castiglione, M. Hawkins, Jr., and X. O. Breakefield, unpublished data). Only one hybrid, NGM5F1D2, with MAO activity lacked a recognizable human X chromosome in all cells examined.

With the exception of NGM5F1D2 (see below) and NGM1J2 (not further studied), there appeared to be an inverse correlation between the total number of human chromosomes in hybrid cells and their levels of MAO activity. Seven lines containing from 3 to 13 human chromosomes had levels of activity from 0.4 to $28.4 \mathrm{pmol} /$ $\mathrm{min} / \mathrm{mg}$ of protein; while six lines containing from one to three human chromosomes had activities from 112.8 to $330.0 \mathrm{pmol} / \mathrm{min} / \mathrm{mg}$ of protein.

The Giemsa-11 staining technique was used to establish whether hybrids contained small fragments of human chromosomal material (Bobrow and Cross, 1974). With this staining procedure, mouse chromosomal material stains darkly except in centromeric regions and human material stains lightly. Of five hybrid lines examined by this technique (20 cells for each line), three, NGM5F1, NGM5F1C2, and NGM5F1D2 (Fig. 2), contained a translocation and one to three small autonomous fragments of human chromosomal material in all cells examined. An- other line, NGM5F1E2, contained one or two very small autonomous fragments in all cells. The fragments present in the first three lines could not be distinguished from each other on the basis of their morphology but appeared to be different from the fragments present in NGM5F1E2, One line, NGM5F1B2, did not have a identifiable human fragment in any of 20 cells examined. These observations indicate that small portions of human chromosomal material can be retained in hybrids either as translocated fragments to mouse chromosomes or as self-replicating units.

Isozyme analysis. Ilybrid lines were examined for the presence of human and mouse forms of two enzymes, PGK and G6PD, which are coded for by genes on the X chromosome of both these species. All hybrid lines which expressed MAO and HPRT activities expressed the human as well as the mouse forms of PGK and G6PD (Table II). Lines lacking MAO and HPRT activities did not express the human forms of PGK and G6PD. The exceptional case, hybrid line NGM5F1D2, expressed MAO activity and the human form of PGK but lacked HPRT activity and the human form of G6PD.

Electrophoretic analysis of MAO. Electrophoretic techniques were employed to confirm the type of MAO expressed in hybrids and to establish whether the flavin polypeptide was encoded in human and/or rodent genes. Binding of $\left[{ }^{3} \mathrm{H}\right]$ pargyline to the flavin polypeptide of 


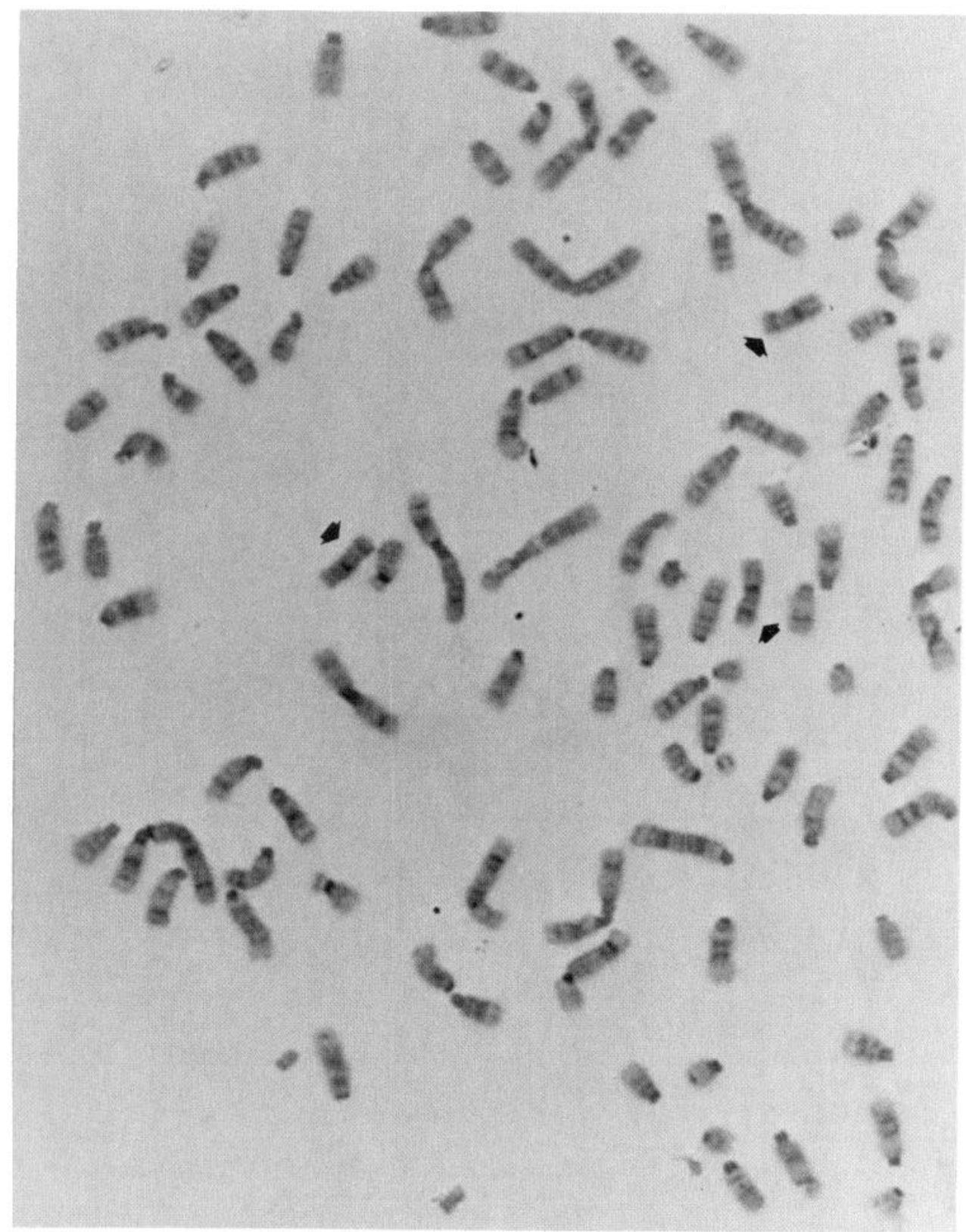

Figure 1. Metaphase spread of Giemsa-banded chromosome from hybrid line NGM5F1. The only human chromosome present is the $\mathrm{X}$, which is present in three copies (marked with arrows). Multiple copies of a single chromosome can arise through non-disjunction of duplicated chromosomes during anaphase of mitosis. This metaphase spread was the only one in those examined from this line which contained multiple copies of the human $\mathrm{X}$ chromosome. Magnification $\times 1500$.

MAO was used to examine the structure of this molecule. Electrophoretic analysis of mitochondrial preparations from the parent GM316 in SDS-polyacrylamide gels revealed a single $\left[{ }^{3} \mathrm{H}\right]$ pargyline-labeled protein band which had an apparent molecular weight of 63,000 similar to the A form of the flavin polypeptide from other human cells (R. M. Cawthon et al., submitted for publication). Further, no band was observed when preparations were incubated prior to $\left[{ }^{3} \mathrm{H}\right]$ pargyline binding with $0.1 \mu \mathrm{M}$ clorgyline. No $\left[{ }^{3} \mathrm{H}\right]$ pargyline-labeled molecules were detected in mitochondrial preparations from N1E-115TG2 cells (Pintar et al., 1979) consistent with their lack of
MAO activity. Electrophoretic analysis of labeled preparations from N1E-115 cells revealed a single band indistinguishable from that present in human cells (Pintar et al., 1979). Two hybrid lines, NGM5F1 and NGM5F1D2, examined by these criteria were identical to the human parent. One hybrid line, NGM1E1, had two bands of $\left[{ }^{3} \mathrm{H}\right]$ pargyline-labeled protein. One (containing about $70 \%$ of the label) coincided with that present in the human parent and was blocked by preincubation with low concentrations of clorgyline (A form). The other (30\%) had an apparent molecular weight of 60,000 similar to the B form of the flavin polypeptide from other human cells 


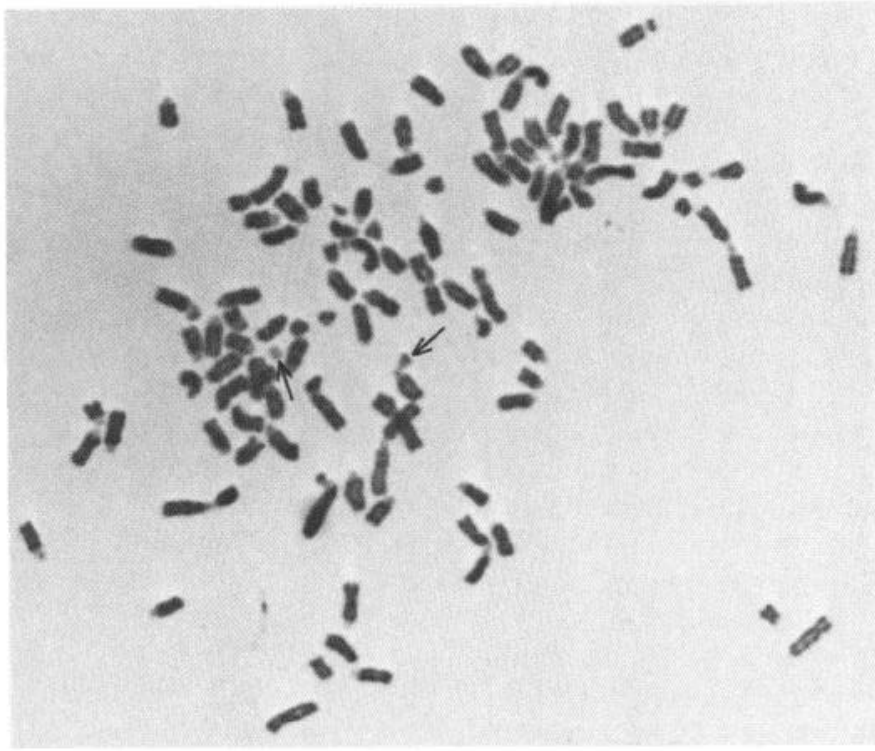

Figure 2. Metaphase spread of Giemsa-11-stained chromosome from hybrid line NGM5F1D2. Mouse chromosomes stain darkly throughout their length except in the centromeric region. Human chromosomes stain lightly. The putative fragments of human chromosomal material are marked with arrows. Magnification $\times 1000$.

(R. M. Cawthon et al., submitted for publication) and was blocked by preincubation with low concentrations of deprenyl (B form). We have no evidence whether the $\mathrm{B}$ form of the flavin polypeptide from mouse and human sources can be distinguished by this procedure; however, other studies indicate that the rat and human forms of this polypeptide are nonseparable (R. M. Cawthon et al., submitted for publication).

Although human and mouse type A flavin polypeptides could not be distinguished by molecular weight, they could be resolved on the basis of internal structural differences using limited proteolysis and peptide mapping. $\left[{ }^{3} \mathrm{H}\right]$ Pargyline-labeled peptide fragments generated by partial digestion with a site-specific protease were resolved in SDS gels. The peptide map of the mouse form of the type A flavin polypeptide was obtained using line N1E-115 (Fig. 3I). Due to the relatively low levels of MAO activity present in GM316 cells, it was not possible to carry out limited proteolysis and peptide mapping on this line. In order to establish peptide maps of the human form of the type A flavin polypeptide, two other human cell types which contain only this type of activity were used, human neuroblastoma line $\mathrm{BE}(2) \mathrm{C}$ (Fig. $3 I I$ ) and human male trophoblast tissue (J. E. Pintar, J. Barbosa, U. Francke, C. M. Castiglione, M. Hawkins, Jr., and X. $O$. Breakefield, unpublished data). The peptide maps generated from both these sources of human MAO-A were similar to each other and distinct from that of mouse MAO-A. Five peptide fragments were obtained by limited proteolysis of the human form; three were similar in molecular weight to fragments generated from the mouse form. However, two peptides with approximate molecular weights of 40,000 and 33,000 were unique to the human form, and a peptide with a molecular weight of 38,000 was unique to the mouse form. Three hybrid lines, NGM1E1, NGM5F1, and NGM5F1D2, were found to exhibit maps similar to that of the human flavin polypeptide (Fig. 3, III to $V$ ). Peptide maps from two other hybrids, NGM1J2 and NGM5C2, also showed the

PEPTIDE MAPPING OF ${ }^{3}$ H-PARGYLINE MAO

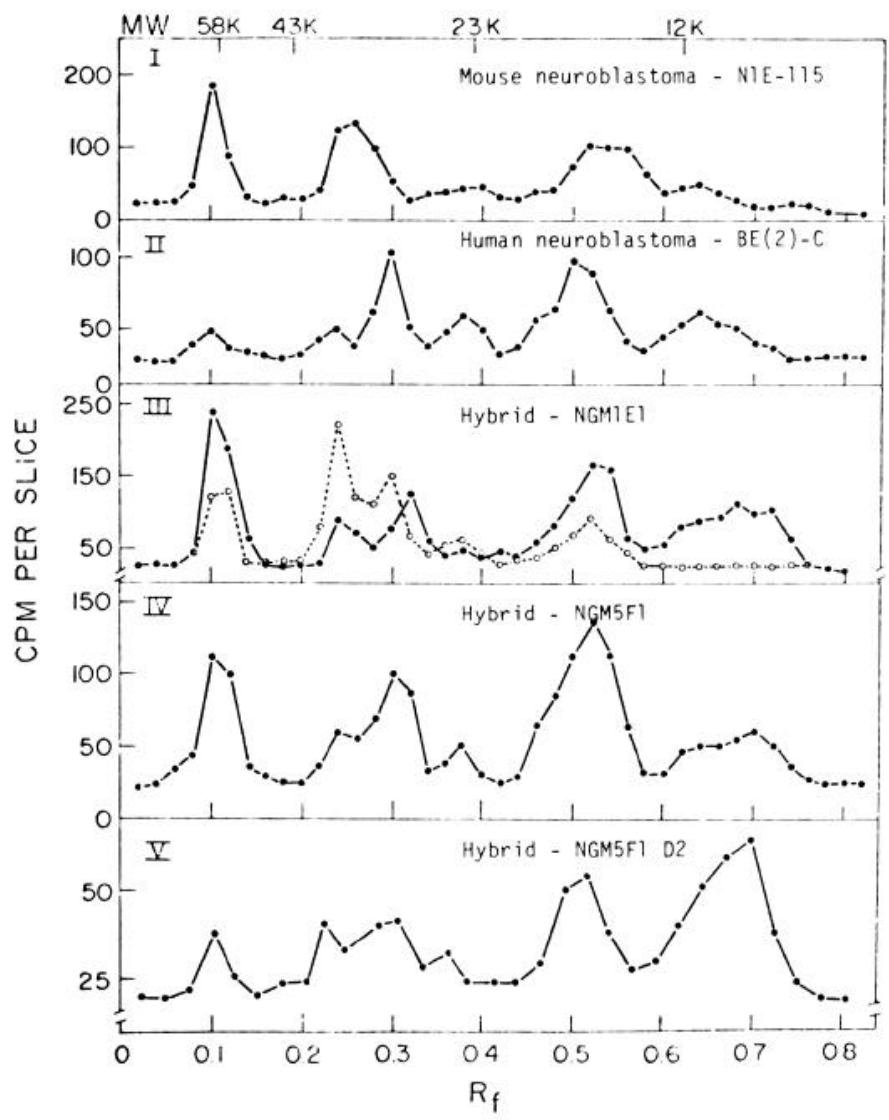

Figure 3. Peptide maps of $\left[{ }^{3} \mathrm{H}\right]$ pargyline-labeled MAO from mouse, human, and hybrid cells. The migration relative to the bromphenol blue dye $\left(R_{f}\right)$ is plotted on the lower abscissa. The migration of standard molecular weight markers is plotted on the upper abscissa. The radioactivity in each 2-mm slice is plotted on the ordinate. $\left[{ }^{3} \mathrm{H}\right]$ Pargyline was bound to MAO in crude mitochondrial preparations as described under "Materials and Methods." After washing and solubilization, preparative polyacrylamide slab gel electrophoresis was carried out in a $7.5 \%$ acrylamide running gel with a $3 \%$ stacking gel, both containing $0.1 \%$ SDS. The portion of the gel containing radioactively labeled MAO was located, cut out, and placed in the sample wells of a proteolytic gel containing a $3 \%$ acrylamide stacking gel and a $15 \%$ running gel. Four identical samples of $\mathrm{MAO}$ for each cell type were loaded into the gels. Staphylococcus aureus V8 protease was added in amounts of $0.125,0.25$, 1.25 , or $2.5 \mu \mathrm{g}$ per well. This protease cleaves predominantly at glutamic acid residues. Electrophoresis was carried out as described (Cawthon and Breakefield, 1979), allowing proteolysis to occur in the stacking gel. The distribution of radioactive peptides in the gel was determined after slicing and solubilization. Analysis for all lines was performed in at least two separate experiments. A representative map illustrating all peptides observed is shown for each line. The leftmost peak is the position of intact MAO. I, Mouse neuroblastoma line N1E-115 (from which N1E-115TG2 was derived); $I I$, human neuroblastoma line $\mathrm{BE}(2) \mathrm{C} ; I I I$, hybrid line NGM1E1; $I V$, hybrid line NGM5F1; $V$, hybrid line NGM5F1D2. 
human pattern (data not shown). Although we cannot exclude the presence of the mouse flavin polypeptide in these hybrids, we estimate that it could represent, at most, $20 \%$ of the labeled flavin polypeptide molecules.

In order to establish that expression of MAO-B activity in these hybrids did not interfere with peptide analysis, peptide maps of lines NGM5F1 and NGM5F1D2 were also generated from mitochondrial fractions which had been preincubated with $1 \mu \mathrm{M}$ deprenyl to block MAO-B activity prior to $\left[{ }^{3} \mathrm{H}\right]$ pargyline binding. These maps (data not shown) were identical to those for the same lines without preincubation with this inhibitor (Fig. 3)

\section{Discussion}

Somatic cell hybrids between human and rodent cells have been widely used to map the chromosomal location of human genes coding for many proteins (Ruddle and Creagan, 1975). This approach can be applied to any human protein if it is expressed in hybrid cells and can be distinguished from the rodent form. Both these criteria are met by $\mathrm{MAO}$. Although the primary function of this enzyme is neurotransmitter catabolism, it is active in both non-neuronal (e.g., human fibroblasts) as well as neuronal (e.g., mouse neuroblastoma) cells and continues to be expressed in hybrid cells. It has not been possible to distinguish human and rodent forms of this enzyme on the basis of electrophoretic mobility using standard techniques (Meera Khan, 1971) since MAO loses activity upon solubilization. Here, we have used a radioactively labeled inhibitor, $\left[{ }^{3} \mathrm{H}\right]$ pargyline, to specifically and irreversibly label the active enzyme in situ. Although the mouse and human flavin polypeptides of this enzyme have similar apparent molecular weights, they can be distinguished on the basis of structural differences by limited proteolysis and peptide mapping. This is the first time, to our knowledge, that this technique has been used in gene mapping.

$M A O$ activity in hybrids correlates with presence of human $X$ chromosome. Somatic cell hybrids were prepared between normal male human fibroblasts which expressed MAO-A and HPRT activities and a mouse neuroblastoma variant lacking both these activities. In these hybrids, human chromosomes were lost rapidly during early cell division, but eventually reached a stable number. By growing hybrids in HAT medium, only cells that retained the human $\mathrm{X}$ chromosome bearing the gene for HPRT or cells immediately adjacent to them (SubakSharpe et al., 1969) can survive. In the initial set of hybrid clones selected in HAT medium, all expressed MAO activity. Two lines with the lowest activity, NGM7 and NGM9, were found to have the human $\mathrm{X}$ chromosome present in 60 to $80 \%$ of the cells examined and to express HPRT activity and the human forms of two Xlinked isozymes, PGK and G6PD. They also contained from 8 to 10 other human chromosomes. Recloning of these lines in HAT medium yielded subclones with MAO activity 4 to 20 times higher than the original clones. Presumably, these subclones have retained the human $\mathrm{X}$ chromosome in a larger percentage of cells and have fewer human chromosomes, associated with higher MAO activity (see below). The two lines with the highest MAO activity, NGM1 and NGM5, were subcloned under non- selective conditions to establish correlations between expression of MAO activity and the presence of specific human chromosomes; all subclones expressed MAO activity. Eight of these hybrid subclones (five derived from NGM1 and three from NGM5) were analyzed karyotypically and all retained the human $\mathrm{X}$ chromosome and a small variable number of human autosomes. For example, line NGM1E1 retained human autosomes 1 and 4, and line NGM5F1 retained no human autosomes. They both expressed HPRT activity and the human forms of PGK and G6PD. These two lines, originating from separate clones, were chosen for further analysis to reduce the chances that the same portion of an unidentifiable human autosome would be present in both.

If expression of MAO activity in these hybrids is dependent on the presence of the human $\mathrm{X}$ chromosome, then selection of lines in 6TG medium for loss of HPRT should result in simultaneous loss of this chromosome and MAO activity. Five lines derived from NGM1E1 by cloning in 6TG medium all lost HPRT and MAO activities, the human $\mathrm{X}$ chromosome, and the two $\mathrm{X}$-linked human isozymes. Similar results were obtained in four subclones derived from NGM5F1 in the presence of $6 \mathrm{TG}$.

In one notable case, however, a hybrid line selected from line NGM5F1 for loss of HPRT activity by growth in 6TG continued to express MAO activity. Further analysis of this line, NGM5F1D2, revealed that it had lost HPRT activity, the human form of G6PD, and a recognizable human $\mathrm{X}$ chromosome but had retained the human form of PGK along with MAO activity. Apparently, the portion of the human $\mathrm{X}$ chromosome containing genes for PGK and MAO had been retained while the terminal portion of the human $\mathrm{X}$ chromosome containing genes for HPRT and G6PD had been lost. This would place the gene for MAO between the centromere and the gene for HPRT on the $\mathrm{q}$ arm of the X chromosome.

It was hypothesized that NGM5F1D'2 contained a small fragment of human $\mathrm{X}$ chromosomal material either translocated to a mouse chromosome or as a self-replicating unit. We have attempted to identify this fragment using the Giemsa-11 technique which distinguishes mouse and human chromosomes on the basis of differences in staining intensity. The large number of chromosomes (model number 134) contributed by the mouse parent and their high degree of rearrangement made it difficult to recognize a small portion of human $X$ chromosomal material by Giemsa banding. NGM5F1D2 cells did contain a translocated piece and a small autonomous fragment of human chromosomal material, although it was not possible to determine whether they originated from the $\mathrm{X}$ chromosome. Further, the presence of human chromosomal fragments was not unique to this line, but also occurred in two sibling subclones, NGM5F1C2 and NGM5F1E2, as well as NGM5F1, all of which have an apparently intact human $\mathrm{X}$ chromosome.

Human MAO flavin polypeptide is expressed in hybrids. The above observations supported the idea that human genes critical to expression of MAO activity in these hybrids are X-linked. In order to establish whether these genes were structural or regulatory, the flavin polypeptides produced by three of these lines, NGM5F1, NGM5F1D2, and NGM1E1, were labeled with $\left[{ }^{3} \mathrm{H}\right]$ par- 
gyline and examined by SDS-PAGE. Resolution of A and $\mathrm{B}$ forms of the flavin polypeptides revealed that the first two lines expressed only the A form, while the latter line expressed both A and B forms. To eliminate the possibility that simultaneous expression of these two forms of the flavin polypeptide might confound subsequent peptide mapping, labeling with $\left[{ }^{3} \mathrm{H}\right]$ pargyline was performed with and without preincubation with low concentrations of deprenyl to block labeling of the B flavin polypeptide. Limited proteolysis and peptide mapping of the A form of the flavin polypeptide in these hybrids yielded peptide fragments which were similar in size to those from the human form of the A flavin polypeptide from human neuroblastoma cells and trophoblast tissue and different from the mouse form of the A flavin polypeptide from mouse neuroblastoma cells. These findings combined with results in the previous section demonstrate that the structural gene coding for the flavin polypeptide of MAO$\mathrm{A}$ is on the human $\mathrm{X}$ chromosome.

It is not known whether the gene coding for the flavin polypeptide of MAO-B is also on the $\mathrm{X}$ chromosome. Because of the evolutionary conservation of genes on the $\mathrm{X}$ chromosome among mammalian species (Ohno, 1967) and structural similarities between A and B forms of the flavin polypeptides in the rat (Cawthon and Breakefield, 1979), it is anticipated that the A and B forms of the flavin polypeptide represent the products of a duplicated gene locus and that both loci are retained on the $\mathrm{X}$ chromosome. Regulatory genes necessary for expression of MAO activity and structural genes coding for the nonflavin-containing polypeptide may or may not be on the human X chromosome.

MAO activity levels vary in hybrids. Levels of MAO activity varied widely among hybrid lines. Some hybrids had levels below that of the human parent, GM316, while most were similar or even above that found in line N1E115. Three possible explanations for this phenomenon are considered here. (1) Variations in the human chromosomal complement may affect levels of activity. Although the presence of a specific human autosome did not correlate with low MAO activity in hybrid lines, there was a clear inverse correlation between the total number of human chromosomes retained by hybrid lines and their level of MAO activity. Since MAO is an integral membrane protein and its activity depends on associated lipids (Houslay et al., 1976), it is possible that the products of genes on other human chromosomes affect the lipid composition of the outer mitochondrial membrane and limit MAO activity. Hybrids with many human chromosomes presumably have a mitochondrial membrane more like the human parental cells than do hybrids with few human chromosomes and thus have MAO activity similar to the fibroblast parent. As human chromosomes are lost, the lipid environment in hybrids resumes the state conferred by the mouse genome and MAO activity levels approach that of the mouse neuroblastoma line, N1E-115, from which the hybrid parent, N1E-115TG2, was derived.

(2) The mouse genome may vary among hybrids. The chromosomal composition of the mouse neuroblastoma parent is heteroploid and varies among cells even in a clonal population. Since independently derived hybrid lines had different neuroblastoma parent cells, they may have differed in their initial mouse chromosomal complement. Further, with subsequent divisions of hybrids, mouse chromosomal material may not have been distributed equally to daughter cells and hence more chromosomal diversity may have been generated. Since we do not know the nature of the "mutation" leading to loss of MAO activity in the N1E-115TG2 parent cells, it is not possible to predict to what extent this mouse genotype can contribute to production of active MAO molecules and to what extent variations in this genotype can affect expression of MAO activity. For example, if the mouse form of the non-flavin-containing polypeptide can interact with the human form of the flavin polypeptide to form an active MAO molecule, then variations in number of copies of the gene coding for the mouse non-flavincontaining polypeptides could affect MAO activity.

(3) Lines may vary in expression of the human and mouse flavin polypeptides. The number of flavin polypeptides present in these hybrid cells could be regulated in many ways. The number of human flavin polypeptides could reflect the number of active copies of the human structural gene and/or the activity of regulatory and processing genes on human or mouse chromosomes. Further, degradation of flavin polypeptides might be hastened in the presence of low amounts of the non-flavincontaining polypeptide or the "flavin attachment enzyme." It is of interest that some cells in one hybrid line with high activity had three human $\mathrm{X}$ chromosomes (Fig. 1) and, presumably, three structural genes for the human type A flavin polypeptide. This line also had high HPRT activity, which suggests that all three $\mathrm{X}$ chromosomes may have been active. Active mouse flavin polypeptides might be produced in the hybrids if a human regulatory gene activates a silent mouse gene. Alternatively, posttranslational modifications encoded in the human genome might allow incompletely processed mouse flavin polypeptides to become active. These last possibilities do not appear, however, to explain the high MAO activity in three hybrid lines with human chromosomes 1, 4 and the $\mathrm{X}$. In these lines, only the human form of the flavin polypeptide could be demonstrated, although minor contributions of the mouse form could not be excluded. This result suggests that the presence of these human chromosomes was not sufficient to activate the mouse flavin polypeptide.

Significance. Levels of MAO activity are inherited in the human population and may have a role in behavior and disease. Analysis of MAO-B in platelets from unrelated and related individuals, including monozygotic and dizygotic twins, has indicated that activity levels are determined to a substantial degree by genetic factors (Nies et al., 1973; Wyatt et al., 1975; Gershon et al., 1980). Further, a rare, temperature-sensitive variant of MAO-B is found in several members of a control pedigree (Bridge et al., 1981). Activity of MAO-A in cultured skin fibroblasts from monozygotic twins was highly concordant, also indicating genetic control (Breakefield et al., 1980). In addition, several lines of evidence indicate that inherited variations in MAO activity can affect neuronal function. Individuals with platelet MAO-B activity in the low normal range appear to have distinctive personality features (Donnelly et al., 1979) and an increased tendency to express certain types of psychiatric illness (Gershon et 
al., 1980; Wyatt et al., 1975). Variations in MAO activity in vivo resulting from administration of MAO inhibitors can lead to mood elevation in depressed patients (Lipper et al., 1979), as well as increased sensitivity to exogenous amines which can lead to poor control of blood pressure (Sandler et al., 1979). Although it is not clear at this time whether inherited variations in the structure of the flavin polypeptide underlie inherited differences in activity levels, knowledge of the chromosomal location of the gene coding for this protein allows us to predict an Xlinked mode of inheritance for at least some of these differences. Our studies suggest a possible role for altered MAO in inherited neurologic and/or psychiatric diseases which have an X-linked mode of transmission and altered biogenic amine metabolism. Candidates for such diseases include the Lesch-Nyhan syndrome (Edelstein et al., 1978); X-linked mental retardation (Jacky and Dill, 1980; Howard-Peebles et al., 1979), the Gilles de la Tourette syndrome (Giller et al., 1980; Kidd et al., 1980), and some forms of bipolar depressive illness (Mendlewicz et al., 1979).

A genetic approach to neurotransmitter metabolism provides a means of establishing the molecular basis of inherited variations in enzyme activity, as well as determining the number of genes and the nature of gene products critical to expression of these enzymes. We have demonstrated $\mathrm{X}$ linkage of the gene coding for the flavin polypeptide of human MAO-A, begun regional mapping of the chromosomal location of this gene, and expect to establish the relationship between this gene and others coding for the flavin polypeptide of MAO-B and the nonflavin-containing polypeptide(s) associated with MAO-A and $\mathrm{M} \Lambda \mathrm{O}-\mathrm{B}$.

\section{References}

Amano, T., E. Richelson, and M. W. Nirenberg (1972) Neurotransmitter synthesis by neuroblastoma clones. Proc. Natl. Acad. Sci. U. S. A. 69: 258-263.

Bobrow, M., and J. Cross (1974) Differential staining of human and mouse chromosomes in interspecific hybrids. Nature 251: 78-79.

Bradford, M. M. (1976) A rapid and sensitive method for the quantitation of microgram quantities of protein utilizing the principle of protein-dye binding. Anal. Biochem. 72: 248-254.

Breakefield, X. O., C. M. Castiglione, and S. B. Edelstein (1976) Monoamine oxidase activity decreased in cells lacking hypoxanthine phosphoribosyltransferase activity. Science 192: 1018-1020.

Breakefield, X. O., S. B. Edelstein, and M. R. C. Costa (1979) Genetic analysis of neurotransmitter metabolism in cell culture: Studies on the Lesch-Nyhan syndrome. In Neurogenetics: Genetic Approaches to the Nervous System, X. O. Breakefield, ed., pp. 197-234, Elsevier-North Holland, New York.

Breakefield, X. O., E. L. Giller, J. I. Nurnberger, C. M. Castiglione, M. S. Buchsbaum, and E. S. Gershon (1980) Monoamine oxidase type $A$ in fibroblasts from patients with bipolar depressive illness. Psychiatry Res. 2: 307-314.

Bridge, T. P., C. D. Wise, S. G. Potkin, B. H. Phelps, and R. J. Wyatt (1981) Platelet monoamine oxidase: Studies of activity and thermolability in a general population. In Genetic Research Strategies in Psychobiology and Psychiatry, E. S. Gershon, S. Matthysse, X. O. Breakefield, and R. D. Ciaranello, eds., Boxwood Press, Pacific Grove, CA, in press.

Callingham, B. A., and D. Parkinson (1979) ${ }^{3} \mathrm{H}$-pargyline binding to rat liver mitochondrial MAO. In Monoamine Oxidase:
Structure, Function and Altered Functions, T. P. Singer, R. W. Von Korff, and D. I. Murphy, eds., pp. 81-86, Academic Press, New York.

Cawthon, R. M., and X. O. Breakefield (1979) Differences in A and $\mathrm{B}$ forms of monoamine oxidase revealed by limited proteolysis and peptide mapping. Nature 281: 692-694.

Chuang, H. Y. K., D. R. Patek, and L. Hellerman (1974) Mitochondrial monoamine oxidase. Inactivation by pargyline. Adduct formation. J. Biol. Chem. 249: 2381-2384.

Cleveland, D. W., S. G. Fischer, M. W. Kirschner, and U. K. Laemmli (1977) Peptide mapping by limited proteolysis in sodium dodecyl sulfate and analysis by gel electrophoresis. J. Biol. Chem. 252: 1102-1106.

Collins, G. G. S., and M. B. H. Youdim (1975) The binding of $\left[{ }^{14} \mathrm{C}\right]$ phenethylhydrazine to rat liver monoamine oxidase. Biochem. Pharmacol. 24: 703-706.

Costa, M. R. C., and X. O. Breakefield (1979) Electrophoretic characterization of monoamine oxidase by ${ }^{3} \mathrm{H}$-pargyline binding in rat hepatoma cells with $\mathrm{A}$ and $\mathrm{B}$ activity. Mol. Pharmacol. 16: 242-249.

Costa, M. R. C., S. B. Edelstein, C. M. Castiglione, H. Chao, and X. O. Breakefield (1980) Properties of monoamine oxidase in control and Lesch-Nyhan fibroblasts. Biochem. Genet. 18: 577-590.

Degnen, G. E., I. L. Miller, J. M. Eisenstadt, and E. A. Adelberg (1976) Chromosome-mediated gene transfer between closely related strains of cultured mouse L cells. Proc. Natl. Acad. Sci. U. S. A. 73: 2838-2842.

Donnelly, C. H., E. Richelson, and D. L. Murphy (1976) Properties of monoamine oxidase in mouse neuroblastoma N1E115 cells. Biochem. Pharmacol. 25: 1639-1643.

Donnelly, E. F., D. L. Murphy, I. N. Waldman, M. S. Buchsbaum, and R. D. Coursey (1979) Psychological characteristics corresponding to low versus high platelet monoamine oxidase activity. Biol. Psychiatry 14: 375-383.

Edelstein, S. B., C. M. Castiglione, and X. O. Breakefield (1978) Monoamine oxidase activity in normal and Lesch-Nyhan fibroblasts. J. Neurochem. 31: 1247-1254.

Epstein, C. J. (1969) Mammalian oocytes: X chromosome activity. Science 163: 1078-1079.

Francke, U., and N. Oliver (1978) Quantitative analysis of high resolution trypsin-Giemsa bands on human prometaphase chromosomes. Hum. Genet. 45: 137-165.

Gershon, E. S., L. R. Goldin, C. R. Lake, D. L. Murphy, and J. J. Guroff (1980) Genetics of plasma dopamine- $\beta$-hydroxylase, erythrocyte catechol- $O$-methyltransferase and platelet monoamine oxidase in pedigrees of patients with affective disorders. In Enzymes and Neurotransmitters in Mental Disease, E. Usdin, P. Sourkes, and M. B. H. Youdim, eds., pp. 281299, John Wiley and Sons, Inc., London, England.

Giles, R. E., and F. H. Ruddle (1973) Production and characterization of proliferating somatic cell hybrids. In Methods and Applications of Tissue Culture, P. Kruse and M. K. Patterson, eds., pp. 475-500, Academic Press, New York.

Giller, E. L., J. G. Young, X. O. Breakefield, C. Carbonari, M. Braverman, and D. J. Cohen (1980) Monoamine oxidase and catechol- $O$-methyltransferase activities in cultured fibroblasts and blood cells from children with autism and the Gilles de la Tourette syndrome. Psychiatry Res. 2: 187-197.

Groshong, R., D. A. Gibson, and R. J. Baldassarini (1977) Monoamine oxidase activity in cultured human skin fibroblasts. Clin. Chim. Acta 80: 113-120.

Hawkins, M., Jr., and X. O. Breakefield (1978) Monoamine oxidase $A$ and $B$ in cultured cells. J. Neurochem 30: 13911397.

Hellerman, L., and V. G. Erwin (1968) Mitochondrial monoamine oxidase. II. Action of various inhibitors for the bovine kidney enzyme. Catalytic mechanism. J. Biol. Chem. 243: 5234-5243. 
Horvitz, H. R. (1973) Polypeptide bound to the host RNA polymerase is specified by $\mathrm{T}_{4}$ control gene 33 . Nature New Biol. 244: 137-140.

Houslay, M. D., K. F. Tipton, and M. B. H. Youdim (1976) Multiple forms of monoamine oxidase: Fact and artifact. Life Sci. 19: 467-478.

Howard-Peebles, P. N., G. R. Stoddard, and M. G. Mims (1979) Familial X-linked mental retardation, verbal disability and marker X chromosomes. Am. J. Hum. Genet. 31: 214-222.

Jacky, P. B., and F. J. Dill (1980) Expression in fibroblast culture of the satellited-X chromosome associated with familial sex-linked mental retardation. Hum. Gen. 53: 267-269.

Kelley, W. N., F. M. Rosenbloom, J. F. Henderson, and J. E. Seegmiller (1967) A specific enzyme defect in gout associated with overproduction of uric acid. Proc. Natl. Acad. Sci. U. S. A. 57: 1735-1739.

Kidd, K. K., B. A. Prusoff, and D. J. Cohen (1980) The familial pattern of Tourette syndrome. Arch. Gen. Psychiatry, in press.

Lipper, S., D. L. Murphy, S. Slater, and M. S. Buchsbaum (1979) Comparative behavioral effects of clorgyline and pargyline in man: A preliminary evaluation. Psychopharmacology (Berlin) 62: 123-128.

Littlefield, J. W. (1964) Selection of hybrids from matings of fibroblasts in vitro and their presumed recombinants. Science 145: 709 711.

Magenis, R. E., T. A. Donlon, and H. E. Wyandt (1978) Giemsa11 staining of chromosome 1: A newly described heteromorphism. Science 202: 64-65.

Mankovits, R., M. Buchwald, and R. M. Baker (1974) Isolation of ouabain-resistant human diploid fibroblasts. Cell 3: 221 226.

Meera Khan, P. M. (1971) Enzyme electrophoresis on cellulose acetate gel: Zymogram patterns in man-mouse and manChinese hamster somatic cell hybrids. Arch. Biochem. Biophys. 145: 470-483.

Mendlewicz, J., P. Linkowski, J. J. Guroff, and H. M. Van Praag (1979) Color blindness linkage to bipolar manic-depressive illness. Arch. Gen. Psychiatry 36: 1442-1447.

Minamiura, N., and K. T. Yasunobu (1978) Bovine liver monoamine oxidase. Arch. Biochem. Biophys. 189: 481-489.

Murphy, D. L. (1978) Substrate-selective monoamine oxidases-inhibitor, species and functional differences. Biochem. Pharmacol. 27: 1889-1893.

Nabholz, M., V. Miggiano, and W. Bodmer (1969) Genetic analysis with human-mouse somatic cell hybrids. Nature 223: $358-363$.

Nies, A., D. S. Robinson, K. R. Lamborn, and R. P. Lampert (1973) Genetic control of platelet and plasma monoamine oxidase activity. Arch. Gen. Psychiatry 28: 834-838.

Ohno, S. (1967) Sex Chromosomes and Sex-linked Genes,
Springer-Verlag, Heidelberg, West Germany.

Oreland, L., and C. J. Fowler (1979) The activity of human brain and thrombocyte monoamine oxidase in relation to various psychiatric disorders. In Monoamine Oxidase: Structure, Function and Altered Functions, T. P. Singer, R. W. Von Korff, and D. L. Murphy, eds., pp. 389-396, Academic Press, New York.

Oreland, L., H. Kinemuchi, and T. Stigrand (1973) Pig liver monoamine oxidase: Studies on the subunit structure. Arch. Biochem. Biophys. 159: 854-860.

Owen, F., A. J. Cross, R. Lofthouse, and V. Glover (1979) Distribution and inhibition characteristics of human brain monoamine oxidase. Biochem. Pharmacol. 28: 1077-1080.

Pintar, J. E., R. M. Cawthon, M. R. C. Costa, and X. O. Breakefield (1979) A search for structural differences in MAO: Electrophoretic analysis of ${ }^{3} \mathrm{H}$-pargyline labeled proteins. In Monoamine Oxidase: Structure, Function and Altered Functions, T. P. Singer, R. W. Von Korff, and D. L. Murphy, eds., pp. 81-86, Academic Press, New York.

Roth, J. A., X. O. Breakefield, and C. M. Castiglione (1976) Monoamine oxidase and catechol- $O$-methyltransferase activities in cultured human skin fibroblasts. Life Sci. 19: 17051710 .

Ruddle, F. H., and R. P. Creagan (1975) Parasexual approaches to the genetics of man. Annu. Rev. Genet. 9: 407-469.

Sandler, M., U. Glover, J. D. Elsworth, R. Lewinsohn, and M. A. Revely (1979) Monoamine oxidase and its inhibition: Some clinical implications. In Monoamine Oxidase: Structure, Function and Altered Function, T. P. Singer, R. W. Von Korff, and D. L. Murphy, eds., pp. 447-456, Academic Press, New York.

Shows, T. B., J. A. Brown, and V. M. Chapman (1976) Comparative gene mapping of HPRT, G6PD and PGK in man, mouse and muntjac deer. In Human Gene Mapping 3, Birth Defects Original Article Series, D. Bergsma, ed., Vol. XII, pp. 436-439, Karger, Basel, Switzerland.

Sottocasa, G. L., B. Kuylenstierna, L. Ernster, and A. Bergstrand (1967) An electron transport system associated with the outer membrane of liver mitochondria. A biochemical and morphologic study. J. Cell Biol. 32: 415-438.

Subak-Sharpe, H., R. R. Bürk, and J. D. Pitts (1969) Metabolic cooperation between biochemically marked mammalian cells in tissue culture. J. Cell Sci. 4: 353-367.

Wurtman, R. J., and J. Axelrod (1963) A specific and sensitive assay for monoamine oxidase. Biochem. Pharmacol. 12: 14391440 .

Wyatt, R. J., R. Belmaker, and D. Murphy (1975) Low platelet monoamine oxidase and vulnerability to schizophrenia. In Modern Problems of Pharmacopsychiatry, J. Mendlewicz, ed., pp. 38-56, Karger, Basel, Switzerland. 